ISSN: 2386-3919 - e-ISSN: 2386-3927

DOI: https://doi.org/10.14201/et2017352161181

\title{
EDUCACIÓN PRENATAL A TRAVÉS \\ DE LA ARTETERAPIA. UNA POSIBLE VÍA \\ DE APOYO A LA PARENTALIDAD POSITIVA
}

\author{
Prenatal education through art therapy. \\ A possible way for positive parenting
}

\author{
Lucía HERVÁs HERMIDA \\ Universidad Autónoma de Madrid \\ Correo-e:lucia.hervas@uam.es
}

Recibido: 5-4-2017; Aceptado: 30-6-2017; Publicado: 30-11-2017

Ref. Bibl. LUCÍA HERVÁS HERMIDA. Educación prenatal a través de la arteterapia. Una posible vía de apoyo a la parentalidad positiva. Enseñanza \& Teaching, 35, 2-2017, 161-181.

RESUMEN: Investigaciones recientes en el campo de la parentalidad positiva defienden la importancia de la promoción de medidas de apoyo a las familias, a través de los programas de educación parental. Es conocida la importancia del periodo prenatal para el desarrollo humano y, sin embargo, la atención a esta etapa se ha realizado tradicionalmente desde el punto de vista biomédico, sin prestar atención a los demás aspectos educativos, emocionales, sociales y de género.

En este sentido, la propuesta de este artículo es plantear una posible vía para el apoyo a la parentalidad positiva, que configure una aportación útil para la pedagogía prenatal como ciencia emergente, a través de la arteterapia. Se muestra, mediante el análisis cualitativo de dos estudios de caso de dos mujeres participantes de dos talleres distintos, las posibilidades que ofrece la arteterapia grupal como vía de educación prenatal, para la exploración de la dimensión creativa de la maternidad y la profundización sobre los vínculos tanto con el bebé que está por nacer, como con la pareja y con el entorno. Así mismo, se favorece el desarrollo de las competencias parentales, poniendo el foco en la toma de conciencia, en el desarrollo personal y en la creación de una matriz de apoyo grupal, en la cual se produce un aprendizaje 
LUCÍA HERVÁS HERMIDA

EDUCACIÓN PRENATAL A TRAVÉS DE LA ARTETERAPIA. UNA POSIBLE VÍA DE APOYO

A LA PARENTALIDAD POSITIVA

compartido. Por último, en las conclusiones se abordan los aspectos de la práctica que favorecen una mejora del bienestar y el desarrollo de una actitud empoderada y resiliente, de la cual se benefician madre e hijo, así como todo su círculo familiar y social.

Palabras clave: educación prenatal; parentalidad positiva; arteterapia; maternidad; vínculo; conciencia.

SUMMARY: Recent research in the field of positive parenting advocates the importance of promoting family support, through parental education programs. On the other hand, the importance of the prenatal period for human development is well known, but attention to this stage has traditionally been done from the biomedical point of view, without paying attention to the other educational, emotional, social and gender aspects.

In this sense, the aim of this article is to propose a possible way to support positive parenting, which will provide an useful contribution to prenatal pedagogy as an emerging science, through art therapy. By the qualitative analysis of two case studies of two women participants from two different workshops, the possibilities offered by group art therapy as a way of prenatal education, for the exploration of the creative dimension of motherhood are shown, and the deepening of the attachment with both the baby, the couple and the environment. Likewise, the development of parental competences is favored, focusing on awareness and personal development, and on the creation of a group support, in which shared learning takes place. Finally, the conclusions deal with aspects of the methodology that foster an improvement in the well-being and the development of an empowered and resilient attitude, benefiting both mother and child, as well as the whole family and social environment.

Key words: prenatal education; positive parenting; art therapy; maternity; attachment; awareness.

\section{INTRODUCCIÓN}

La etapa perinatal es un momento trascendental en la vida y el desarrollo de los seres humanos, y así lo atestiguan numerosas investigaciones. Sin embargo, el fenómeno de la vida intrauterina ha sido tratado casi exclusivamente desde la perspectiva biomédica, y la educación maternal que conocemos ha estado centrada principalmente en los aspectos físicos del embarazo, especialmente en la preparación al parto, sin apenas atender a los demás aspectos que conlleva.

En este sentido, la propuesta de la pedagogía prenatal como ciencia emergente es ampliar este concepto de la educación prenatal, atendiendo a todas sus dimensiones y comprendiendo la complejidad de los procesos, agentes y participantes que actúan en ella desde el punto de vista físico pero también afectivo, a través del cuidado de la madre y de su contexto social (De la Herrán, 2015; Hurtado, Cuadrado y De la Herrán, 2015). 
Por otro lado, se ha producido en los últimos años una toma de conciencia desde el ámbito de la intervención familiar y en concreto desde el modelo de la parentalidad positiva, sobre las necesidades de apoyo a las familias, como principales agentes educativos, de socialización y de desarrollo. Una posible respuesta a esta necesidad es la educación parental, que se realiza a través de programas de formación de padres y madres, sin embargo, llama la atención que incluso dentro de éstos apenas existe una atención específica a la etapa prenatal, estando los programas en su mayoría centrados en la edad escolar.

La propuesta de este artículo es abrir una vía de educación prenatal a través de la arteterapia. El lenguaje artístico, así como los procesos creadores dentro de los talleres grupales de arteterapia, ofrecen a las mujeres un marco idóneo para la formación, a través de la reflexión y toma de conciencia sobre su estado, y la elaboración de todo el proceso de transformación que acontece, paralelo a la gestación del nuevo ser. Además, desde la perspectiva de género, y teniendo en cuenta que aún hoy en día la responsabilidad de la crianza recae especialmente sobre las madres, a través de los talleres de arteterapia se promueve el empoderamiento (Florschutz, 2013), la resiliencia y el desarrollo de la inteligencia maternal, aquella que permite que las mujeres, aun en circunstancias adversas, sean capaces de desarrollar la crianza de sus hijos en condiciones de buenos tratos (Barudy, Dantagnan, Comas, y Vergara, 2014).

\section{PARENTALIDAD POSITIVA Y PROGRAMAS DE EDUCACIÓN PARENTAL}

Según la Recomendación Rec de políticas de apoyo a la parentalidad positiva, ésta se define como:

Aquel comportamiento de los padres fundamentado en el interés superior del niño, que cuida, desarrolla sus capacidades, no es violento y ofrece reconocimiento y orientación que incluyen el establecimiento de límites que permitan el pleno desarrollo del niño (Comité de Ministros a los Estados Miembros, 2006: 3).

Dicho documento insta a los Estados a asumir políticas a favor de las familias, y hace hincapié en la importancia de promover medidas de apoyo y programas de intervención socioeducativa, como los programas de educación parental, que en general son de carácter preventivo, universal y abierto. Éstos se definen como procesos que promueven el desarrollo personal de los padres y madres, y favorecen una mejora de las prácticas educativas y las competencias parentales, definidas como «las capacidades prácticas de los padres para cuidar, proteger y educar a sus hijos, y asegurarles un desarrollo sano» (Barudy y Dantagnan, 2005: 77).

Como todo aprendizaje, el desarrollo de las competencias parentales es un complejo proceso que se nutre de las propias experiencias del padre y la madre en su infancia, así como de otras influencias sociales y culturales. Exige una gran capacidad de adaptación y flexibilidad, ya que evoluciona de manera paralela al desarrollo de las necesidades de los hijos en cada momento. Este proceso, que 
distingue la parentalidad biológica de la social, y que comienza en la etapa prenatal, es el foco de la educación parental desde la perspectiva de la prevención y la promoción de los buenos tratos.

Se han definido unos principios fundamentales en los que se basa el modelo de la parentalidad positiva, el cual está fundamentado en la promoción de los vínculos afectivos y actitudes responsables y no violentas, los cuales se ha observado que favorecen procesos de desarrollo saludables (Rodrigo, Máiquez y Martín, 2010). Sin embargo, incluso dentro del modelo de la parentalidad positiva existen voces críticas que cuestionan el peligro de que algunos programas pongan el acento en la instrucción, reduciendo el rol de padres a su aspecto funcional para la socialización de los hijos, e imponiendo una ideología y unas prácticas que son ajenas a las familias (Bernal y Sandoval, 2013). Según Martínez (2009) una buena intervención familiar debe estar guiada por el respeto a la diversidad en las necesidades y valores de las familias, poniendo el foco en el desarrollo de los aspectos potenciales, más que en sus dificultades.

De la revisión de los programas existentes destacamos como referente los denominados de tercera generación (Martín-Quintana et al., 2009), los cuales se focalizan en la mejora del funcionamiento familiar como sistema, comprendiendo la complejidad del contexto y partiendo de las necesidades y recursos de las familias, y no de un modelo ideal de crianza. Se trata de un modelo basado en una metodología experiencial, que tiene como objetivo la reconstrucción del conocimiento dentro del contexto real de las familias, a partir de la elaboración compartida en el proceso grupal. En este modelo se pretende que los padres tengan una participación activa en todo el proceso y, sobre todo, que tomen las riendas sobre sus propios cambios, fomentando así la resiliencia.

\section{EDUCACIÓN PRENATAL A TRAVÉS DE LA ARTETERAPIA PARA LA MATERNIDAD}

La arteterapia para la maternidad forma parte de la arteterapia familiar, la cual procede del desarrollo de las teorías de intervención familiar, y especialmente del enfoque sistémico. Según este modelo holístico, eje vertebral que conecta la parentalidad positiva, la pedagogía prenatal y la arteterapia, la familia es comprendida como un sistema cambiante, una compleja red de relaciones en constante interacción, que a su vez pertenece a un contexto social y cultural (Kerr, Hoshino, Sutherland, Parashak y McCarley, 2011).

Las ventajas que aporta la arteterapia a este enfoque tienen que ver con la especificidad del lenguaje artístico, el cual aporta una alternativa a la comunicación verbal y permite la exploración de las dinámicas del sistema familiar a través de la creación artística (Riley y Malchiodi, 2003).

Dentro de la arteterapia familiar, la arteterapia para la maternidad ofrece un tipo de atención centrada en la comprensión de las necesidades durante la gestación y crianza, y el acompañamiento a los procesos de transformación propios de esta etapa, desde una perspectiva de género. La maternidad, desde este enfoque, 
más que un estado alcanzado tras el parto, es un complejo y largo proceso de transformación y crisis personal y existencial (Gutman, 2003) que se inicia en algún momento de la etapa prenatal, y evoluciona de manera paralela con la criatura. Este proceso de transformación puede ser considerado incluso en un proceso de iniciación, entendida ésta como transformación de la psique, derivando en un crecimiento personal y espiritual profundo (Swan-Foster, 2012). En este sentido, de acuerdo con Fernández (2012), la gestación en sí misma puede ser comprendida como un proceso creativo, que se desarrolla en el cuerpo de la mujer embarazada, a todos los niveles, físico, emocional, social y espiritual, sobre sí misma, sobre la criatura que está engendrando y sobre su entorno. A través de la exploración de esta dimensión creativa de la maternidad se pretende facilitar la elaboración de la experiencia en toda su complejidad, siendo la creación artística una vía de encuentro consigo misma y con la criatura que crece en su interior.

Las imágenes creadas por las mujeres embarazadas en los talleres de arteterapia son además un elemento muy útil para la comprensión de las experiencias subjetivas acerca de la relación entre el vínculo prenatal y el desarrollo de la identidad materna (Hocking, 2007). A través de la observación de las imágenes creadas por las mujeres, el taller de arteterapia puede ofrecer no sólo una vía para la expresión y elaboración, sino que puede servir también para la prevención de posibles problemáticas y patologías asociadas (Swan-Foster, 1990; Swan-Foster, Foster y Dorsey, 2003; Swan-Foster, 2012).

Por otro lado, la realización de actividades creativas en grupo facilita que se genere un espacio de apoyo mutuo (Demecs, Fenwick y Gamble, 2011). Según Hogan (2003), el espacio grupal de las sesiones de arteterapia con enfoque de género facilita el intercambio de información entre las madres, poniendo el foco en la expresión emocional, la reflexión personal y en la creación de vínculos de apoyo. Estos vínculos configuran la denominada "matriz de apoyo» que, según Stern, Bruschweiler-Stern y Freeland (1999), refiere a esa red de relaciones formada por los vínculos con mujeres de confianza en los cuales las mujeres encuentran tanto los conocimientos y recursos como el sostén que necesitan para desarrollarse como madres, constituyendo un importante agente educativo.

En este sentido la arteterapia para la maternidad se encuentra en la intersección entre lo educativo y lo terapéutico, desde la concepción del desarrollo personal. Cabe destacar a este respecto la posibilidad que ofrece la arteterapia para desarrollar competencias personales e interpersonales, a través de la exploración de nuevas posibilidades de relación y el desarrollo del empoderamiento y de la resiliencia. Según García (2013) es posible, a través del diálogo con los materiales y con la obra, dar una oportunidad para que se produzca una transformación de los estilos de apego y desarrollar un aprendizaje sobre las habilidades interrelacionales, con el consecuente impacto positivo sobre el vínculo con la criatura que está por nacer. Por último, Grosser (2007) hace hincapié en el desarrollo de la resiliencia como factor de protección y la posibilidad que ofrece la arteterapia para ayudar a las mujeres a conectar con su maternidad de manera positiva, una 
maternidad que se convierte entonces en una fuente de motivación, aprendizaje, superación y crecimiento personal.

\section{Metodología}

El objetivo principal de esta investigación, el cual es parte de un proyecto de tesis doctoral, está centrado en el diseño de una metodología de intervención en arteterapia para la maternidad y las familias como vía de educación parental, a través de la puesta en práctica en contextos reales, y su posterior evaluación. Se pretende indagar acerca de las posibilidades de la arteterapia para el apoyo a la parentalidad positiva, y reflexionar sobre cómo esta propuesta puede además ser una aportación para la educación prenatal, desde la especificidad de las posibilidades que ofrece el lenguaje artístico y de la atención a los procesos de creación que acontecen durante la gestación.

Para ello, el enfoque escogido es cualitativo y plural, como una combinación de enfoques y métodos, que permiten ampliar la diversidad de perspectivas frente al problema de investigación (Alonso-Sanz, 2013). Se ha realizado un proceso cíclico de puesta en práctica y evaluación que contiene las siguientes fases, las cuales están inspiradas en el modelo en espiral propuesto por Elliot (1986) para el proceso de la investigación-acción:

1. Diseño de una propuesta de intervención.

2. Implementación de la intervención en un contexto real y observación.

3. Evaluación y reflexión.

Para obtener una comprensión global del proceso, nos basaremos en el método de los estudios de caso (Stake, 1995), desde un enfoque fenomenológico (Gilroy, 2006), mostrando dos casos concretos, como ejemplos ilustrativos. Se realiza una descripción profunda y detallada del proceso, atendiendo a la complejidad y particularidad de cada caso en sí mismo, incluyendo imágenes, así como la percepción particular de las participantes sobre la experiencia. 
LUCÍA HERVÁS HERMIDA

EDUCACIÓN PRENATAL A TRAVÉS DE LA ARTETERAPIA. UNA POSIBLE VÍA DE APOYO

A LA PARENTALIDAD POSITIVA

TABLA 1

Categorías de análisis

a) Necesidades, dificultades y recursos de las mujeres en su maternidad, atendiendo a la situación personal de las participantes.

b) Objetivos de la intervención y grado de consecución de éstos, basándonos en las necesidades detectadas y en los principios de la parentalidad positiva.

c) Aspectos referentes a la adecuación del marco, la orientación y la metodología de la intervención.

d) Aspectos relacionados con los vínculos de apego y el proceso interrelacional.

e) Aspectos relacionados con la creación artística, el proceso creativo y la obra.

f) Participación, implicación y grado de satisfacción de las participantes con el proceso.

Respecto a los casos mostrados, el primero se trata de una mujer embarazada primigesta, que participó en un taller de arteterapia para la maternidad, realizado en 2014, en el que participaron cinco mujeres, siendo un grupo mixto que incluía mujeres embarazadas y madres de niños pequeños. En el segundo caso, una mujer embarazada con un hijo de 26 meses, participante de un taller de arteterapia en el que asistieron siete familias (madres y padres con sus hijos en edad preescolar). Los talleres tuvieron una duración de cuatro y seis sesiones, respectivamente, de dos horas de duración, más una entrevista individual previa y una sesión de evaluación mediante grupo de discusión, en ambos casos.

\section{TABLA 2}

Instrumentos de recogida de datos

- Cuestionario inicial.

- Entrevista individual semiestructurada.

- Diario de campo.

- Hojas de registro de las sesiones.

- Registro audiovisual.

- Cuestionario de evaluación.

- Sesión de grupo de discusión.

Finalmente, se ha procedido a realizar un análisis cualitativo, de contenido textual, con apoyo visual, buscando la comprensión profunda de cada caso. Se han seguido dos pautas principales, la revisión permanente y la reducción de los datos (Tójar, 2006), y se han desarrollado tres fases (Gutierrez, 2005), con el apoyo del software de análisis cualitativo Atlas.ti:

1. Lectura y transcripción completa de todas las fuentes de datos. 
2. Estructuración de los datos en categorías, y búsqueda de interpretaciones y significados.

3. Reflexión y análisis de los datos obtenidos, elección de pasajes significativos y síntesis e interpretaciones.

\section{PRIMER CASO: NADIA ${ }^{1}$}

Nadia es una mujer, con estudios superiores, que actualmente no trabaja y convive con su pareja, con quien está casada, y se encuentra en el tercer mes de su primer embarazo. En la entrevista inicial comenta no haber acudido todavía a ningún curso de educación maternal, aunque sí tiene intención de hacerlo, y, sobre la atención que está recibiendo en su embarazo, dice echar de menos más apoyo en la consulta médica, un seguimiento más continuado. Para ella es importante este apoyo, "porque si no -dice- me va a dar una angustia que me voy a morir".

Sus fuentes de apoyo son personas de su entorno, familia, pareja y otras madres con experiencia, de quienes dice necesitar consejos prácticos. También dice apoyarse en la búsqueda de información a través de libros, Internet, etc. Lee mucho, pero a veces cree que tanta información puede ser perjudicial, porque se preocupa en exceso, "quiero estar preparada para las posibles opciones que puedan venir».

Antes de comenzar el taller cree que la arteterapia, que no conocía, le puede ayudar a «sacar el plano artístico, creativo, de la persona para que te pueda ayudar, para conocerte a ti misma, afrontar los problemas y demás, para conocerme, identificar problemas que me asustan» y le da especial valor al aspecto del autoconocimiento: "Cuando yo consiga conocerme a mí misma [...] todo lo que me sirva para identificar mis problemas y mis carencias». Cree que el arte no se le da bien, pero considera que el embarazo es un momento de cambio, de apertura de mente: «Soy totalmente negada, pienso que puede ser un buen momento para intentar ver, si le doy otra vuelta, a ver cómo me puede ayudar esto en esta nueva etapa [...] esto es una forma de abrirme a otros aspectos que no conocía».

En la primera sesión, la propuesta es elaborar un Mandala ${ }^{2}$ en un recorrido por la memoria, desde los recuerdos de la infancia, hasta el momento actual. En su mandala (ver Figura 1) se observa que tiene gran importancia en el centro el tema de la familia de origen, y en concreto la figura de ella con sus padres. Cuando ha terminado el dibujo, le sugiero reelaborarlo desde su mirada actual, y ella decide

1. Para preservar la intimidad de las participantes, los nombres aquí mostrados son ficticios. Así mismo se usará la primera persona del plural en femenino como genérico, desde un punto de vista inclusivo. También, en los pasajes referentes a la intervención se utilizará la primera persona con el fin de transparentar y dar sentido a mi posición como arteterapeuta dentro del relato.

2. Un mandala es, en esencia, una representación del cosmos dentro de un círculo. 
rellenar las siluetas con corazones. "Cuando lo he visto desde adulta, me parecía que estaba vacío, y lo he rellenado".

\section{FIGURA 1}

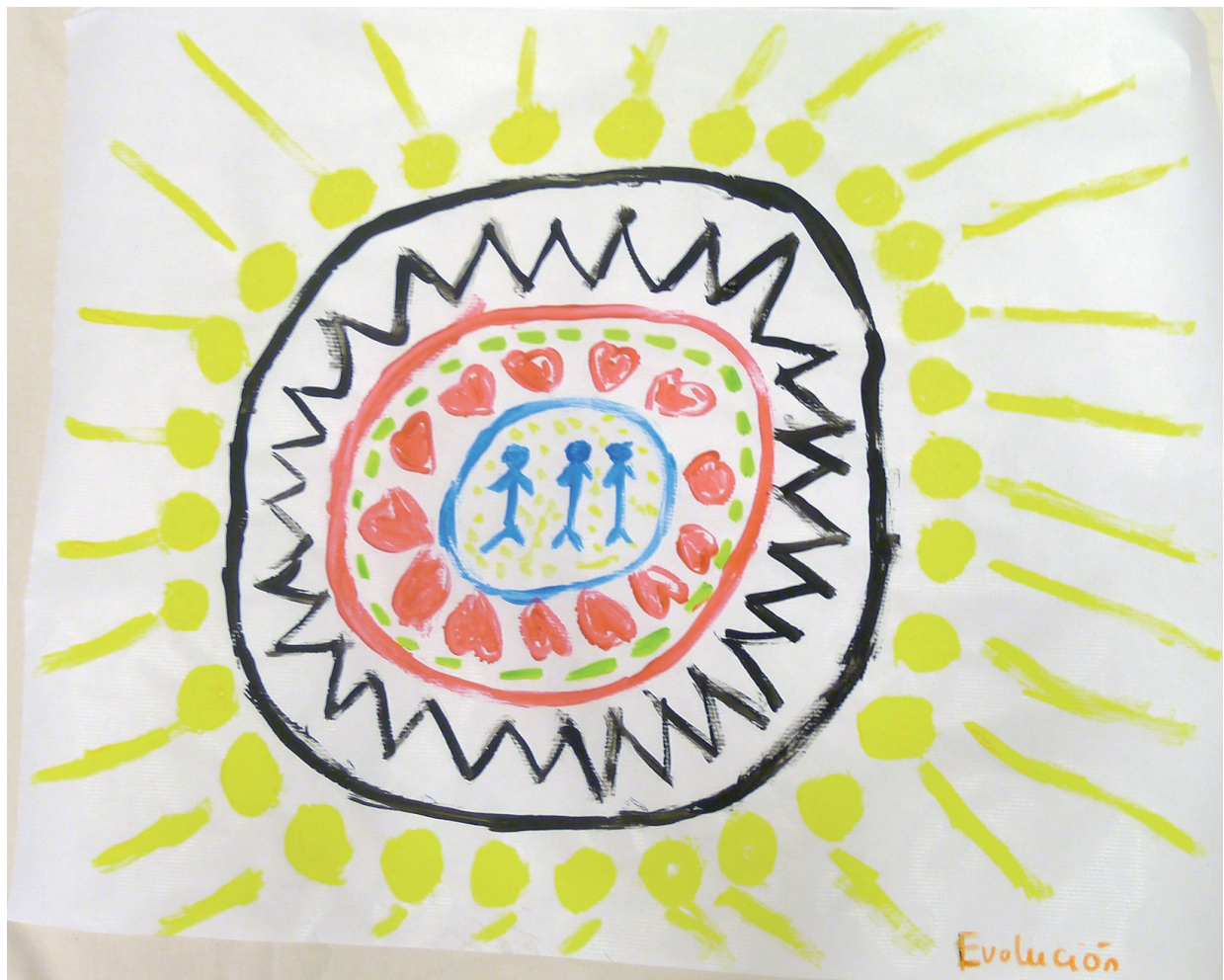

Después en la ronda comenta haber sentido inseguridad al principio con los materiales, "no sabía qué hacer», y después más confianza. Al hablar de la obra, se muestra al principio algo insegura, ganando cada vez más confianza en el proceso de contar lo que significa para ella. Conecta con la satisfacción a través del amarillo, un color que le hace sentirse orgullosa, "me está gustando cada vez más, cuanto más lo cuento, ni añadiría ni quitaría nada».

Al finalizar la sesión realizamos una dinámica de cohesión grupal, generando con un ovillo de lana la red simbólica que formamos en el grupo, sosteniendo la red con nuestras manos, mientras verbalizamos nuestro compromiso y expectativas con el taller. En este momento ella verbaliza «quiero aprender de vuestra experiencia, [...] no sé qué decir, yo he venido aquí muy nerviosa, y creo que participar en esto me va a dar tranquilidad y seguridad». 
LUCÍA HERVÁS HERMIDA

EDUCACIÓN PRENATAL A TRAVÉS DE LA ARTETERAPIA. UNA POSIBLE VÍA DE APOYO

A LA PARENTALIDAD POSITIVA

En la segunda sesión viene muy emocionada, y dice que le contó a su familia lo que hizo en la sesión anterior, "me impactó, me llenó, y lo quería transmitir". Comenta que se lo enseñó a su pareja y le preguntó si se sentía representado en su pintura, y él le contestó que se "veía» representado en un corazón. Entonces ella, dijo, sentía que había conseguido representar lo que quería.

En esta sesión nos centramos en el objetivo de trabajar la comunicación y habilidades interrelacionales: comunicación, escucha, empatía, asertividad, etc. Comenzamos con unas dinámicas de expresión corporal en parejas, que comenzaban con una toma de contacto con la compañera, mientras ambas se ponían la mano en el corazón para escucharse mutuamente. Ella en este momento sonriendo decía "Yo es que tengo dos" ${ }^{3}$. Después de esta toma de contacto la propuesta consistía en acompañarse mutuamente caminando y explorando la sala con los sentidos, mientras una cerraba los ojos, y la otra la acompañaba y guiaba, cuidando de la compañera. En este proceso, iba dándoles consignas para prestar atención a las sensaciones que percibían, y para tomar conciencia sobre diferentes aspectos. Después de haber experimentado ambas con los dos roles, realizamos una pintura compartida, con témperas, en la que representar su experiencia del proceso.

En la ronda final, cuando compartimos cómo ha sido la experiencia, dice haber sentido al principio, al cerrar los ojos, una sensación de angustia, de caer de un precipicio. Habla de una sensación de pérdida, que podría interpretarse como una metáfora de la sensación de desorientación ante el cambio que supone la maternidad. Después, hablando del acompañamiento de su compañera, dice que se ha sentido muy tranquila, "como si cayera en un jardín con flores", y lo ha representado en su dibujo (ver Figura 2). Habla de necesidad de mantener contacto físico, le decía "no me sueltes", y comenta la importancia del contacto, del acompañamiento de su compañera, en quien encontraba apoyo, manteniendo el contacto con ella misma, "me relajaba, porque confiaba en ella, pero estaba atenta". Narra cómo el hecho de estar embarazada le ha afectado a su confianza en su propio cuerpo, ya que ahora, dice, le da más miedo. Habla de la miedo a caerse, y que se mueve con más cautela y respeto, y esto nos lleva a reflexionar durante la sesión sobre los miedos, que a veces son "sabios", protectores, y le llevan a buscar apoyos cálidos, protegiendo a su bebé. Sobre su pintura dice que quería representarse a sí misma cayendo del precipicio, y dibuja una montaña con una caída sobre flores. Después comenta que su compañera dibujó una $\mathrm{C}$ que ella interpretó de "creatividad», y entonces ella puso la T, de «tranquilidad». Sobre el proceso de creación, comenta que al principio estaba muy claro dónde pintaba cada una, teniendo el papel dividido, y después se miraron y se dieron el consentimiento para pintar cada una en la parte de la otra, avanzando en la confianza en la interrelación.

3. Se refiere a dos corazones, el suyo y el de la criatura en su vientre. 


\section{FIGURA 2}

Pintura compartida. Título: Confianza

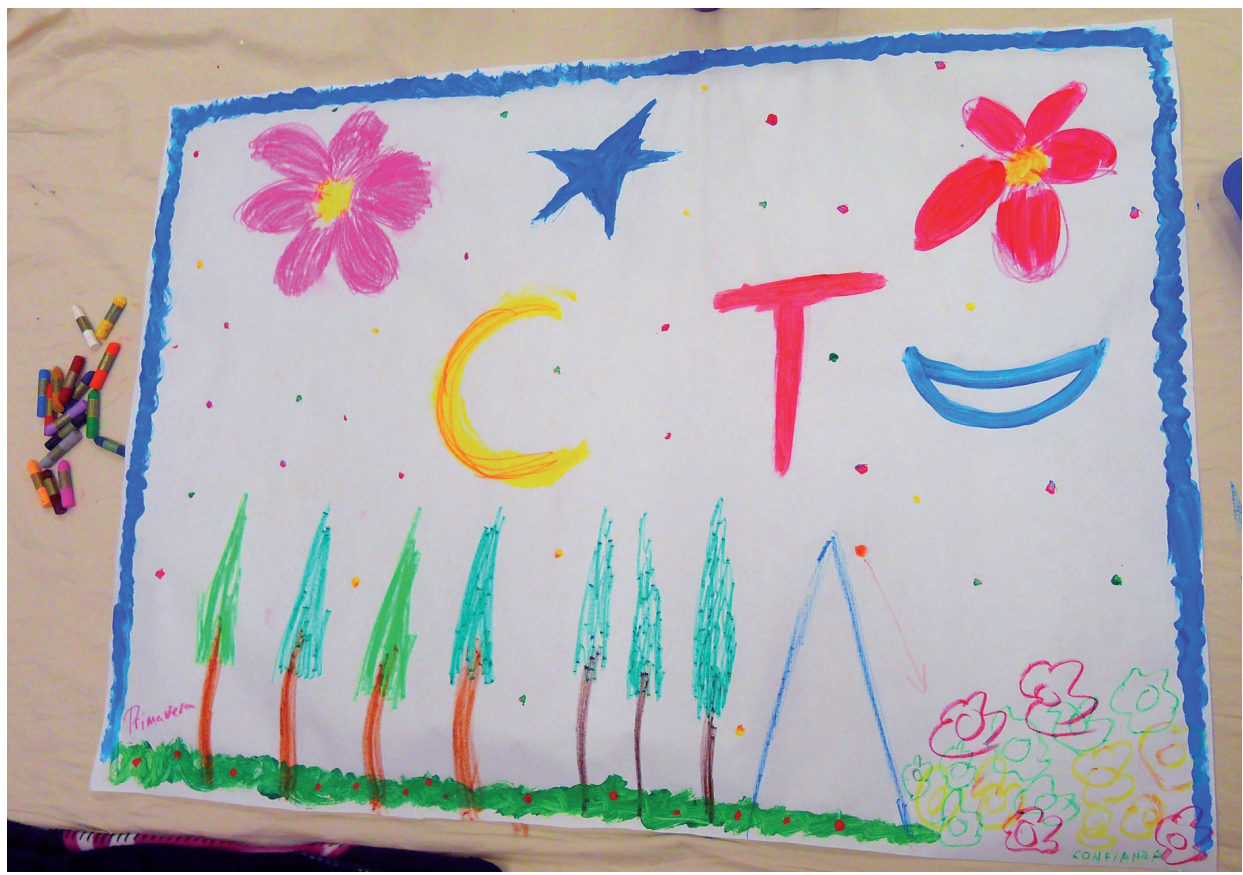

En la tercera sesión trabajamos la conciencia corporal, a través de la danza, la visualización y el modelado con arcilla. Tras unos breves ejercicios de calentamiento, la propuesta consiste en sentir el cuerpo, prestando atención a la zona del vientre y las caderas, mediante una danza libre que ocupó la primera parte de la sesión. Después realizamos una relajación, seguida de una visualización guiada, en la que pusimos atención sobre el útero y el cuerpo como creador de vida. Finalmente les propuse modelar con los ojos cerrados su cuerpo maternal, y ella creó una obra con forma de recipiente cóncavo, que contenía una figurita, simbolizando al bebé.

Sobre esta sesión, ya en la ronda final, comenta que en todo momento ha sentido mucho a su bebé y se sentía muy conectada con él: "Vale, estás aquí conmigo, y nos estamos conectando los dos». Sobre la arcilla, comenta que necesita calor, para que se consolide, siendo este comentario una metáfora de la necesidad de calor que también tiene la criatura que nace en su vientre. También dice que otros días le ha costado más arrancar, pero en esta sesión no, dice que ha conectado mucho con esta parte, que se ha sentido fluida. El momento más significativo es cuando comenta que al abrir los ojos sintió una gran sorpresa al ver al bebé, porque reflejaba la imagen lo que ella tenía en mente (ver Figura 3). 
FIGURA 3

Obra de Nadia en arcilla

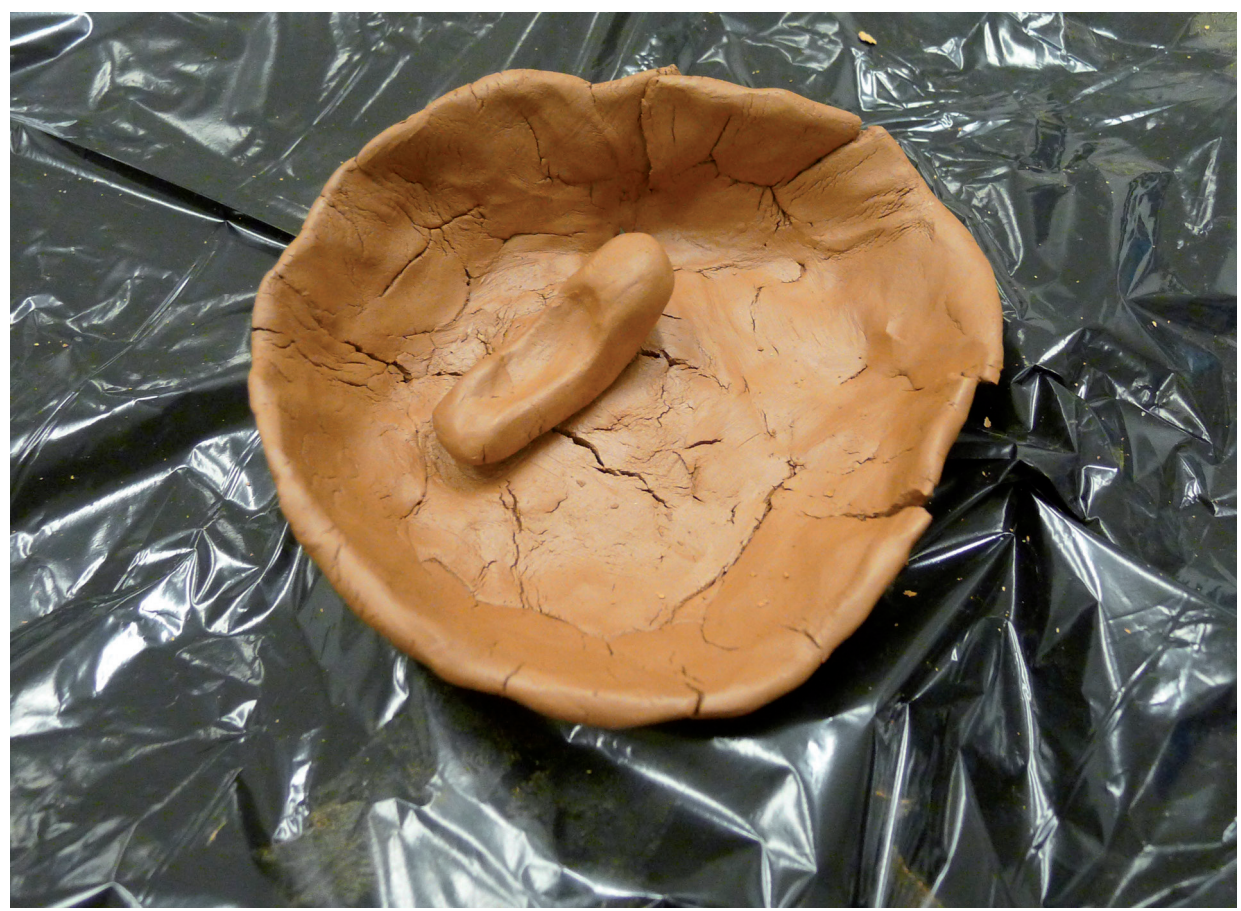

Posteriormente, en la sesión de grupo de discusión, comenta que ésta ha sido su sesión preferida, mencionando que había alcanzado un estado de relajación total, de paz interior y "conexión conmigo misma». Sobre ello escribe: "Relajación muy útil que después he aplicado en mi vida».

En la cuarta y última sesión, el objetivo estaba centrado en la elaboración de una visión de futuro esperanzadora, creativa y resiliente, para lo que hicimos primero un ejercicio de visualización, imaginando cómo nos gustaría que fuera nuestro futuro como madres, una vez hayan crecido nuestros hijos. Acabamos la sesión creando una pintura, y componiendo un poema colectivo inspirado en la visualización.

Nadia comienza la sesión comentando que es una persona muy nerviosa, y que tiene problemas para dormir. Dice que durante la semana un día puso en práctica el ejercicio de relajación y visualización y le fue muy útil para calmar los nervios, "por que si no me va a afectar a mí, va a repercutir al bebé, y no puede ser [...] vamos a parar y ver las cosas desde otro punto de vista».

Sobre la experiencia, en la ronda final dice que le han venido varias imágenes, y que se ha sorprendido porque hasta ahora sólo visualizaba al bebé y su 
habitación, pero en la visualización se veía con el niño más mayor. Se ve en exteriores, en la playa, en situaciones de ocio y tiempo libre. Dice que se veía "todos juntos, los tres»: su marido, su bebé y ella, en imágenes divertidas, pero también haciendo los deberes. Dibuja puntos alrededor del dibujo y dice que refieren a la familia, le recuerda a las mesas cuando se juntan toda la familia, los amigos, etc. Dice haber tenido una sensación de calor, de abrigo, de tener apoyos, de cobijo, al recrear su entorno: "He visto que puedo necesitar a la gente y recibir ese apoyo, de mi familia y de la gente que yo quiero".

Tras finalizar las sesiones, en el cuestionario de evaluación dice: «Me ha aportado sobre todo poder reflexionar sobre mis sentimientos, mi manera de ser, formas de afrontar problemas", algo que está muy vinculado con las expectativas que tenía en un inicio. En la sesión de evaluación hace hincapié en la importancia de las rondas finales, el momento de compartir acerca de la experiencia, para ayudarle a darse cuenta de cosas. Dice que le ha ayudado a comprender el significado de sus dibujos y darles un sentido e incluso volver a transformarlos, dándoles nuevos significados.

También menciona la importancia de los materiales en el taller, ante los que al principio se sentía insegura y con ciertos reparos, «llevaba años sin coger unas pinturas... pero ha sido acercarme y conectar con la niña que llevo dentro". Poder conectar con este lado infantil que hay dentro de cada una comentan que también puede ser útil porque les va a servir para después hacer actividades creativas con sus hijos, en su día a día, mejorando sus habilidades parentales y propiciando momentos de calidad en familia.

\section{Segundo CASO: Begoña}

Begoña es una mujer trabajadora con estudios artísticos superiores, en su segundo embarazo (de seis meses), con un hijo de 26 meses, que convive con su pareja. En el cuestionario y la entrevista inicial comenta haber tenido una buena percepción de apoyo en su maternidad, tanto por parte de su familia, como dentro de su trabajo y de su círculo social. Ha asistido a un curso de educación maternal que ofrecía el servicio público de salud, el cual le ha sido útil, aunque dice hacer echado de menos allí que se tuviera en cuenta la individualidad. Comenta haber realizado una búsqueda de apoyos a través de actividades dirigidas a mujeres embarazadas o madres, incluyendo un grupo de lactancia, las cuales le han permitido crear una "tribu» en la que sentirse respaldada, y un espacio donde tener vida social acompañada de su hijo, un espacio del que dice que «es un proceso de todos, porque todos tenemos los mismos problemas al mismo tiempo». Sin embargo, menciona tener una sensación de soledad y una falta de empatía por parte del padre, con quien tiene dificultades en la relación. Con respecto a sus necesidades menciona la necesidad de espacio para sí misma, y encontrar apoyo emocional, por lo que su expectativa respecto al taller se resume en: «Tener tiempo para reconocer las emociones, saber qué me pasa, verme». 
LUCÍA HERVÁS HERMIDA

EDUCACIÓN PRENATAL A TRAVÉS DE LA ARTETERAPIA. UNA POSIBLE VÍA DE APOYO

A LA PARENTALIDAD POSITIVA

Begoña se incorpora al grupo en la tercera sesión, aunque asiste desde el comienzo. En la primera sesión no puede permanecer debido a que su hijo rechaza participar, y tiene una rabieta que no conseguimos calmar, por lo que decide marcharse, con gran frustración. En la segunda sesión no puede asistir por un viaje de trabajo, y se reincorpora en la tercera, con cierto temor de que se repita la rabieta del primer día.

En esta sesión, los objetivos estaban centrados en la estimulación sensorial y la exploración y mejora del vínculo a través de las sensaciones primarias del sentido del tacto. El taller estaba estructurado en dos partes, una primera parte en la que la propuesta consistía en la realización de un masaje, y una segunda parte dedicada a la creación con harina. Ambas propuestas son generadoras de experiencias sensoriales y de contacto, y en las que indagar acerca del caos y el desbordamiento, situaciones habituales en el día a día de la crianza, y que requieren de una gran flexibilidad.

Durante la ronda inicial, Begoña comenta que ha tenido una semana muy buena, pues ha estado de viaje durante tres días, y su hijo ha estado muy agradecido a su vuelta. Es la primera vez que tienen una separación tan larga, y comenta que ha sido muy liberador para ella, aunque ha supuesto una acumulación de tarea en casa.

Comenzamos a movernos haciendo unos suaves estiramientos, para tomar conciencia del cuerpo, tras lo cual comenzamos con el masaje en parejas, de manera que una de las dos adultas se tumba y la otra compañera, acompañada de los niños, le ofrecen un masaje. Para ello propongo unas pautas concretas que propician un tipo de masaje más imaginativo y creativo que facilita el acercamiento y el contacto.

En el momento de dar el masaje, se vuelca físicamente con su compañera, así como para recibir el masaje se deja hacer, relajada, riéndose mientras recibe. Llama la atención que, en este momento, otros de los niños de la sala se acercan y se unen a ellas, por lo que durante un rato son muchas las manos que la acarician, mostrando los niños mucha ternura, cuidado e interés en el bebé que está dentro de su tripa.

Después, en el momento de dar los masajes a los niños, su hijo se despista y se levanta, no quiere permanecer quieto, interesándose por lo que hacen los demás, y jugando con objetos que hay en la sala. Ella le sigue el juego, aunque parece algo nerviosa, mientras los demás finalizan el masaje. Después, cuando comenzamos el trabajo con la harina, comienza ella sola, pues su hijo parece no tener interés. Este momento ella lo menciona en la ronda final como un momento de crisis que recuerda a su frustrante experiencia en la primera sesión: "No vamos a hacer lo que aquí hemos venido a hacer». En ese momento, la acompaño y le sugiero comenzar aunque su hijo no haya entrado todavía en el círculo, dejándole que se incorpore poco a poco. Finalmente participa y colaboran, «él me decía las cosas y yo las he hecho", aunque continúan teniendo otros momentos de conflicto, con la elección del color, ya que le consulta qué color quiere, pero él tarda en decidirse y 
ella dice "he estado a punto de no respetarle». Entonces el niño elige el color verde, pero ella dice que le hubiera gustado el naranja, pues el verde no le gusta mucho. Cuando le pregunto si ella siente que ha hecho lo que ella quería hacer dice que sí, con un tono irónico, que desvela su frustración.

Sobre ello, en la sesión de grupo de discusión, posteriormente, comentó: «A mí me gustó [...] que trabajamos como el respeto a ti mismo, en la elección de los colores. Se vio claramente cuando tú pasabas a un segundo plano por lo que prefería tu hijo. Yo este día me hice consciente de que priorizo lo que él quiere».

Después en la ronda final, comenta haber disfrutado mucho el masaje que le han dado "dos adultas y todos los niños de la sala». Comenta que ha sido muy agradable la sensación de cuidado, y especialmente en la zona de las piernas, que es una zona que no suele tocarse mucho desde que está embarazada.

En una sesión posterior, la quinta del proceso $^{4}$, la cual estaba también dedicada a la autoconciencia corporal y la exploración de las relaciones, los límites y el contacto, esta situación de conflicto pudo tener una evolución con un impacto favorable sobre su embarazo y el vínculo con su bebé. La propuesta era una actividad de mapeado del cuerpo, en la que dibujamos las siluetas de nuestro cuerpo sobre el papel, para después expresar pictóricamente dentro de nuestra silueta nuestro estado emocional, pintando y dejando huellas sobre el papel en forma de caricias de color.

Tras la ronda inicial y un breve calentamiento a través de juegos de expresión corporal, comenzamos con la propuesta, dibujando nuestra silueta sobre el papel, situado en el suelo. Begoña decide tumbarse sobre el papel, de lado, de manera que en su silueta queda constancia de la forma de su barriga. Comienza entonces a dibujar dentro de la silueta, y su hijo la acompaña, pero entran en conflicto cuando él se pone a pintar encima de la silueta del bebé, algo que a ella no le gusta, y se lo expresa, "y me ha pedido que le hiciera a él también uno". Entonces ella le dibuja a su hijo una silueta sobre la que dibujar, momento desde el cual se encuentran ambos dibujando uno junto al otro, pero cada uno concentrado en su propio espacio, sin más conflicto.

En ese momento ella puede centrarse en su cuerpo y su embarazo, y dice que ha querido dibujar bien marcado «un corazón, porque estoy en una etapa muy instintiva y amorosa a nivel familiar», y se explaya también en la representación del bebé que hay dentro de su vientre (ver Figura 4).

4. Se ha obviado de la narración la cuarta sesión por no ser relevante. 


\section{FIGURA 4}

Pintura colectiva en la que se observa la silueta de Begoña y el bebé en su vientre

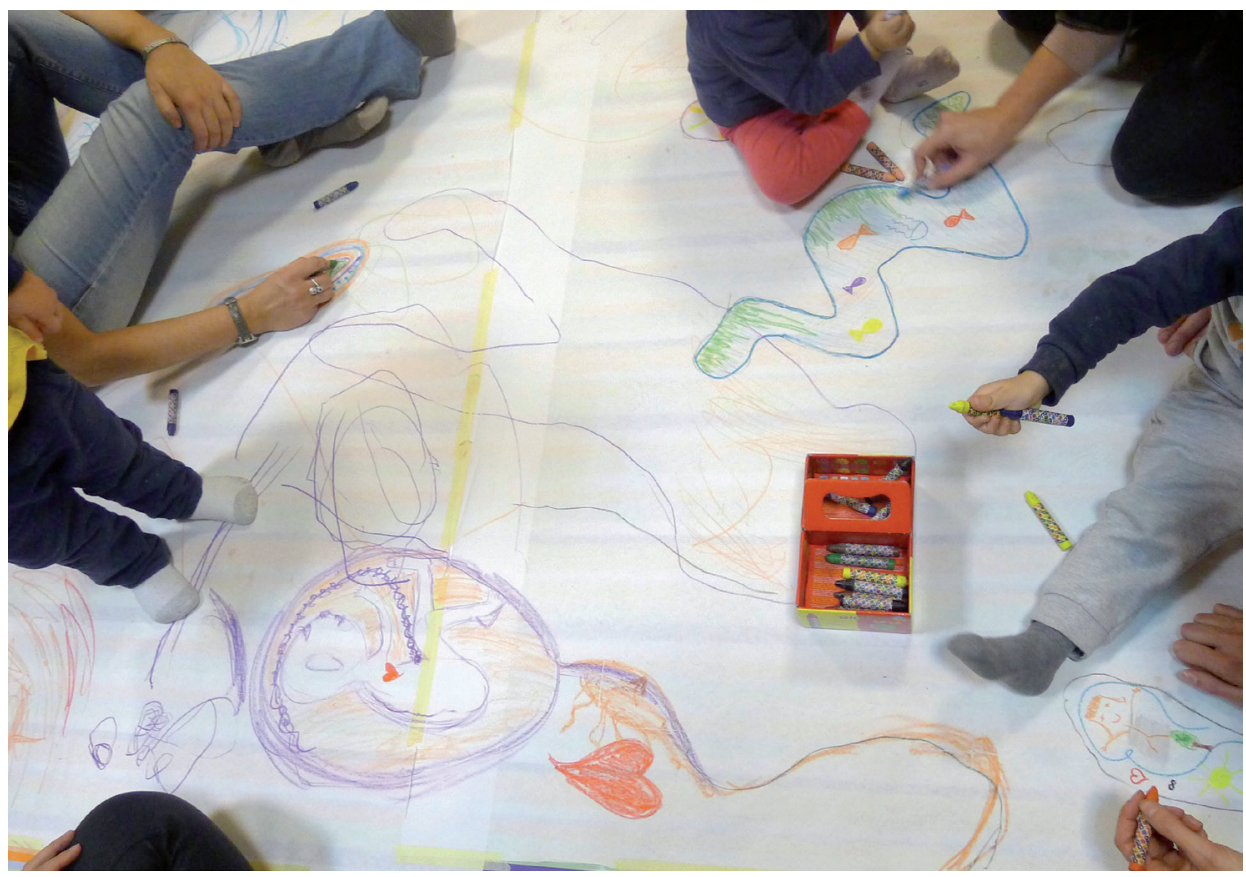

Después, les propongo pintarse las manos y dejar una huella sobre el papel, como caricia, y dice: "Lo he querido poner en el bebé, y le he dado una caricia en mí (refiriéndose a la silueta), y también no quería dejar a Fernando ${ }^{5}$ sin una caricia» (ver Figura 5).

5. Se refiere a la silueta de su hijo sobre el papel. 
EDUCACIÓN PRENATAL A TRAVÉS DE LA ARTETERAPIA. UNA POSIBLE VÍA DE APOYO

A LA PARENTALIDAD POSITIVA

\section{FIGURA 5}

Evolución de la pintura colectiva. Obsérvense las "caricias» de pintura sobre las siluetas

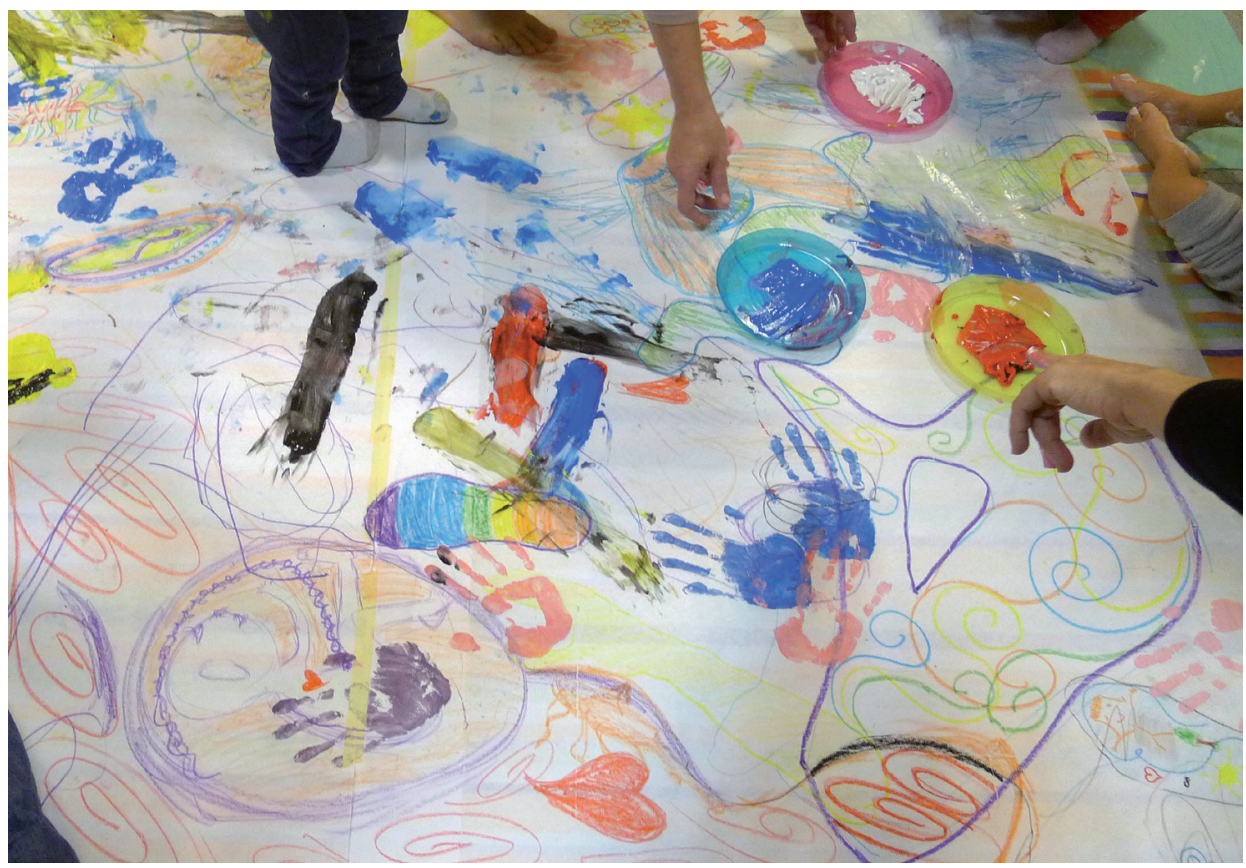

Sobre esta experiencia, en la ronda final, habla de su proceso de aprendizaje respecto a los límites, y cómo al principio le respetaba siempre su libertad, y después ha empezado a ser más capaz de respetar sus propios límites como mujer y como persona: "Yo antes le consentía muchas cosas que ahora no, y estoy otra vez recuperando mi espacio, y él también, le veo que descansa mejor, está más contento...".

Tras compartir esto con el grupo comenta también su propia necesidad de descanso y espacio personal, y su preocupación ante la llegada de su segundo hijo, encontrando alivio al contarlo: «Me falta porque no sé cómo hacerlo, ni cómo, ni cuando... y después ya viene el siguiente».

\section{CONCLUSIONES}

Tal y como hemos observado, en ambos casos la participación en el taller ha facilitado el desarrollo de un proceso educativo, a través de la toma de conciencia, la reflexión y el desarrollo de recursos, desde dos situaciones distintas. Quisiera 
hacer de nuevo hincapié en la cualidad más específica que aporta la arteterapia, con la presencia del lenguaje artístico, en tanto que permite desvelar aspectos que de otro modo serían difícilmente abordados. La expresión artística facilita la recreación de las relaciones familiares, como hemos visto en ambos casos, potenciando los vínculos y permitiendo elaborar las situaciones de conflicto. A través de la representación es posible, además, traer a la sesión a todos los miembros de la familia, incluida la criatura que está por nacer, y otros miembros ausentes. Tal y como mencionaba Begoña, en la sesión de discusión, «a mí me gustó mucho que la silueta era un reflejo de mí y de mi bebé dentro, y me gustó que mi hijo reivindicara que estuvieran ahí su padre y su abuelo».

Por otro lado, me parece importante reflexionar acerca de la dificultad de la evaluación de la eficacia de la intervención, y las limitaciones de la investigación, por lo que el enfoque ha estado centrado en la detección de las necesidades concretas de las participantes, las cuales pueden ser variables dependiendo del grupo, del contexto y del momento puntual, extrayendo como conclusión, por lo tanto, la imposibilidad por el momento de generalizar y plantear programas cuyo diseño pueda ser de aplicación universal. Tal y como se ha observado de los resultados de la experiencia, la eficacia de la intervención parece que no tiene tanto que ver con las propuestas concretas planteadas, sino con la flexibilidad del marco, así como con los aspectos que se mueven en lo interrelacional. Este aspecto de la flexibilidad es comentado por algunas de las participantes durante los grupos de discusión como uno de los aspectos más positivos, que algunas describían como la capacidad de la intervención de adaptarse a cada una de las participantes, poniendo el foco en el autodescubrimiento personal.

En este sentido, los objetivos y temas propuestos, de los cuales se ha derivado la estructura de las sesiones, si bien son temas generales extraídos del marco teórico, han sido planteados de una manera lo suficientemente amplia como para permitir que cada una de ellas se pudiera desenvolver en la propuesta, desde su propia vivencia. Esta diversidad de experiencias, que para cada participante ha podido tener un impacto distinto, se amplificaba y cobraba sentido educativo en la puesta en común final, a través de la experiencia compartida.

En este sentido, y tal y como veíamos en el marco teórico, considero que otro aspecto importante para el éxito de la propuesta se encuentra en la creación de un espacio de apoyo grupal, donde el resto de participantes ejercen una función de sostén mutuo, constituyendo un importante agente educativo. Tal y como menciona Hogan (2003), para ellas resulta muy tranquilizador encontrar reflejo en otras mujeres en la misma situación y sentir que no están solas ante las dificultades. Desde un punto de vista de género esto es especialmente importante, en tanto que se permite la expresión de sentimientos difíciles o ambivalentes, que pueden encontrar su espacio, disolviéndose así la tensión y el habitual sentimiento de culpa por no sentirse a la altura de lo que supuestamente una «buena madre» debe sentir.

En este sentido, parece ser positiva y enriquecedora la mezcla de perfiles, de mujeres embarazadas, madres y padres en diferentes momentos respecto a la 
relación con sus hijos. Como veíamos, parece que promueve la comunicación entre las participantes, independientemente de su situación, facilitando experiencias de aprendizaje compartido. Las participantes del primer grupo, en la sesión de grupo de discusión, creían que es muy positivo que las embarazadas puedan escuchar lo que les pasa a otras mujeres, pues esto es algo de lo que habitualmente nadie les habla: «Da igual que tengan un año, o siete, porque esto dura para toda la vida [...] como embarazada esto te viene muy bien porque es la vida real».

Así mismo, los dos diferentes formatos, de grupo de madres y de grupo de familias, han tenido experiencias así como abordajes metodológicos muy diferentes. La presencia de los niños, más allá de las diferentes etapas que puedan estar atravesando, aportaba una gran diferencia a la realidad de las sesiones, desplazando el foco del trabajo hacia la díada o el sistema familiar, en una búsqueda del equilibrio a la atención de las necesidades de ambos.

En este sentido, Begoña comentaba sobre su experiencia que le hubiera gustado poder realizar sesiones en paralelo alternando ambos formatos, el de familias, junto a los niños, y de grupo de madres, sin hijos, para poder tener tiempo para compartir con su hijo, y también tiempo para ella misma. Mencionaba: «Cuando tengo al niño mi atención es para él, no me sé dividir». Sin embargo, resulta paradójico cómo esta necesidad de tener un espacio propio para muchas de ellas resulta imposible de satisfacer, debido a la falta de apoyos en quienes confiar el cuidado de sus hijos. A este respecto, la posibilidad de trabajar dentro de un equipo multidisciplinar sería una opción óptima, tal y como defiende Proulx (2003), ya que permitiría ofrecer una atención más específica a las madres y a los padres, mientras los niños también son atendidos, e incluso ofrecer un acompañamiento individualizado durante el proceso.

En cualquier caso, y a pesar de las limitaciones, si bien en ambos casos la duración del proceso ha sido breve, y sería deseable poder realizar un proceso más profundo y de mayor duración, podemos afirmar que la propuesta es capaz de cumplir sus objetivos y promover la toma de conciencia y una actitud de empoderamiento en las participantes, y el desarrollo de recursos. Sobre ello manifestaba Begoña en la sesión de grupo de discusión: "A mí las seis sesiones me parecían insuficientes antes de hacerlas, pero ahora me parecen bien, de hecho en vez de seis he hecho tres, y he sentido que he crecido y me he hecho consciente de varias cosas".

Este aspecto del autodescubrimiento parece esencial para el objetivo de la educación parental, así como dentro de las premisas de la pedagogía prenatal, ya que tal y como mencionaba De la Herrán (2015) no se pretende la mera instrucción o desarrollo de capacidades, sino que el objetivo principal es el desarrollo de la conciencia, comprendiendo la educación desde el punto de vista del desarrollo humano. De acuerdo con la afirmación de Martín-Quintana y sus colaboradores (2009), el objetivo de la educación parental debe estar tanto en la promoción de las habilidades educativas de los padres y las madres, como en el desarrollo de las competencias personales e interpersonales, ya que ambas están relacionadas con el desarrollo de los hijos e hijas. Tal y como dice Martínez, la meta esencial de 
toda intervención con las familias se resume en «fortalecer y enriquecer el bienestar individual y familiar» (Martínez, 2009: 16), algo que, como hemos visto, es posible gracias a la arteterapia.

\section{REFERENCIAS BIBLIOGRÁFICAS}

Alonso-Sanz, M. A. (2013). A favor de la Investigación Plural en Educación Artística. Integrando diferentes enfoques metodológicos. Arte, Individuo y Sociedad, 25 (1), 111-119.

Barudy, J. y Dantagnan, M. (2005). Los buenos tratos a la infancia: Parentalidad, apego y resiliencia. Barcelona: Editorial Gedisa.

Barudy, J.; Dantagnan, M.; Comas, E. y Vergara, M. (2014). La inteligencia maternal. Barcelona: Editorial GEDISA.

Bernal Martínez de Soria, A. y Sandoval Estupiñan, L. Y. (2013). "Parentalidad positiva» o ser padres y madres en la educación familiar/Positive Parenting or Being Parents in the Family Education. Estudios sobre Educación, 25, 133-149.

Comité de Ministros a los Estados Miembros (2006). Recomendacion Rec 19. Recuperado el 20 de octubre de 2015. http://www.msssi.gob.es/ssi/familiasInfancia/parentalidadPos2012/docs/informeRecomendacion.pdf.

De la Herrán Gascón, A. (2015). Educación prenatal y Pedagogía prenatal. Revista Ibero-americana de Educação, 69 (1), 9-38.

Demecs, I. P.; Fenwick, J. y Gamble, J. (2011). Women's experiences of attending a creative arts program during their pregnancy. Women and Birth, 24 (3), 112-121.

Fernández Bocanegra, J. J. (2012). La maternidad, Un proceso de creación en el espacio terapéutico: el estudio de un caso. Trabajo de Fin de Máster. Universidad de Valladolid.

Florschutz, A. (2013). The Art of Birth. United Kingdom: Engage Press.

García Pradas, N. (2013). El vínculo en un taller de arteterapia con mujeres embarazadas. Trabajo de Fin de Máster. Universidad de Valladolid.

Gilroy, A. (2006). Art therapy, research and evidence-based practice. London: Sage.

Grosser Villar, H. (2007). El embarazo como un renacer. Una intervención de Arte Terapia en una mujer embarazada víctima de violencia intrafamiliar. Proyecto Final para Optar al Curso de Especialización de Postítulo en Terapias de Arte, Mención Arte Terapia. Universidad de Chile, Santiago de Chile.

Gutiérrez Pérez, M. del R. (2005). Los estudios de casos: una opción metodológica para investigar la educación artística. En R. Marín Viadel (ed.). Investigación en educación artística: temas, métodos y técnicas de indagación sobre el aprendizaje y la enseñanza de las artes y culturas visuales (pp. 151-174). Granada: Universidad de Granada.

Gutman, L. (2003). La maternidad y el encuentro con la propia sombra. Buenos Aires: Nuevo Extremo.

Hocking, K. L. (2007). Artistic narratives of self-concept during pregnancy. The Arts in Psychotherapy, 34 (2), 163-178.

Hogan, S. (2003). Gender issues in art therapy. London: Jessica Kingsley Publishers.

Hurtado Fernández, M.; Cuadrado Nicoli, S. y De la Herrán Gascón, A. (2015). Hacia una Pedagogía Prenatal. Una propuesta educativa. Revista Iberoamericana de Educación, 67 (1), 151-168.

Kerr, C.; Hoshino, J.; Sutherland, J.; Parashak, S. T. y McCarley, L. L. (2011). Family art therapy: Foundations of theory and practice. New York: Routledge. 
LUCÍA HERVÁS HERMIDA

EDUCACIÓN PRENATAL A TRAVÉS DE LA ARTETERAPIA. UNA POSIBLE VÍA DE APOYO

A LA PARENTALIDAD POSITIVA

Martín-Quintana, J. C.; Máiquez Chaves, M.; Rodrigo López, M.; Byme, S.; Rodríguez Ruiz, B. y Rodríguez Suárez, G. (2009). Programas de educación parental. Intervención Psicosocial, 18 (2), 121-133.

Martínez González, R.-A. (2009). Programa guía para el desarrollo de competencias emocionales, educativas y parentales. Secretaría General Técnica, Ministerio de Sanidad y Política Social.

Proulx, L. (2003). Strengthening emotional ties through parent-child-dyad art therapy: Interventions with infants and preschoolers. London: Jessica Kingsley Publishers.

Riley, S. y Malchiodi, C. A. (2003). Family art therapy. En Handbook of art therapy. New York: Guilford Press.

Rodrigo López, M. J.; Máiquez Chaves, M. L. y Martín Quintana, J. C. (2010). Parentalidad positiva y politicas locales de apoyo. Madrid: FEMP-Federación Española de Municipios y Provincias.

Stake, R. E. (1995). Investigación con estudio de casos. Madrid: Ediciones Morata.

Stern, D. N.; Bruschweiler-Stern, N. y Freeland, A. (1999). El nacimiento de una madre: cómo la experiencia de la maternidad te hará cambiar para siempre. Barcelona: Paidós.

Swan-Foster, N. (1990). Images of pregnant women: Art therapy as a tool for transformation. The Arts in psychotherapy, 16 (4), 283-292.

Swan-Foster, N. (2012). Pregnancy as a Feminine Initiation. Journal of Prenatal and Perinatal Psychology and Health, 26 (4), 207.

Swan-Foster, N.; Foster, S. y Dorsey, A. (2003). The use of the human figure drawing with pregnant women. Journal of reproductive and infant psychology, 21 (4), 293-307.

Tójar Hurtado, J. C. (2006). Investigación cualitativa: comprender y actuar. Editorial La Muralla. 